\title{
The physiotherapy management of patients undergoing abdominal surgery
}

Julie C Reeve PhD, MSc, Grad Dip Phys

Senior Lecturer, School of Clinical Sciences, Faculty of Health and Environmental Studies, AUT University, Auckland, New Zealand

lanthe Boden M. Health Sci, B. Physiotherapy

Cardiorespiratory Supervisor Physiotherapist, Physiotherapy Department, Launceston General Hospital, Launceston, Tasmania, Australia

\section{ABSTRACT}

Abdominal surgery is performed to remove cancerous tissue, to resolve visceral tissue perforations or to remove inflammatory bowel segments, benign growths or vascular aneurysms. Postoperative complications, including pulmonary complications, are common following abdominal surgery and physiotherapy aims to prevent and treat many of these complications. Much of the literature investigating physiotherapy interventions is over a decade old and advances in surgery, including minimally invasive surgery and fast track pathways, require physiotherapists to re-evaluate their practices. This narrative review aims to examine the evidence investigating the effectiveness of physiotherapy interventions and apply this to contemporary surgical practices. Recommendations for practice and research are outlined.

Reeve J, Boden I (2016) The Physiotherapy Management of Patients undergoing Abdominal Surgery New Zealand Journal of Physiotherapy 44(1): 33-49. doi: 10.15619/NZJP/44.1.05

Key words: Physiotherapy, General surgery, Abdomen, Evidence-Based Practice

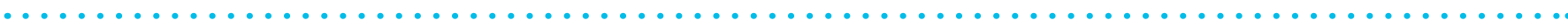

\section{INTRODUCTION}

Abdominal surgery is the most frequently undertaken surgery type in Australia and New Zealand. At least 130,000 operations were performed in 2012-2013 across 246 hospitals in Australia alone and this is increasing by $2-5 \%$ per year (AlHW 2013). World-wide, approximately 500 to 1,000 procedures per 100,000 head of population are performed annually in developed countries (Weiser et al 2008).

Postoperative complications are common following major abdominal surgery with one third to half of all patients having some type of complication following their operation (Aahlin et al 2015, Hamel et al 2005). Complications, such as postoperative pulmonary complications (PPC), prolonged postoperative ileus and the sequelae of prolonged immobility are potentially preventable with physiotherapy interventions. Physiotherapists have routinely provided care to patients undergoing abdominal surgery since the 1950s (Cash 1955, Innocenti 1996) and research investigating the effectiveness of physiotherapy following abdominal surgery is generally over a decade old (Pasquina et al 2006). Since this time, major advances in surgery, such as minimally invasive surgical techniques and improved perioperative management, have significantly reduced postoperative complications and length of hospital stay
(LOS) (Spanjersberg et al 2015). These advances require a reevaluation of physiotherapy for patients undergoing abdominal surgery.

\section{What is abdominal surgery?}

Abdominal surgery can be categorised according to the location and length of the main incision. Upper abdominal surgery (UAS) involves an incision above or extending above the umbilicus and lower abdominal surgery (LAS) involves incisions wholly below the umbilicus (see Table 1 and Figure 1). Surgery may be open (with an incision $>5 \mathrm{~cm}$ ), laparoscopic or a combination of both. Historically, laparoscopic surgery was predominantly performed for cholecystectomy and gynaecological procedures only. Recently, major procedures such as bowel, liver, stomach, oesophagus and kidney resections are being performed laparascopically or as laparoscopic handassisted surgery (minimally invasive surgery), whereby an additional incision allows a hand to pass into the abdomen for surgical manipulation and tissue removal (see Figure 2). Although, minimally invasive surgery involves longer anaesthetic times (Owen et al 2013) compared with the equivalent open procedure, accelerated recovery, reduced complication rates and shorter LOS have been demonstrated (Spanjersberg et al 2015). 
Table 1. Type and location of abdominal surgical procedures

\begin{tabular}{|c|c|c|}
\hline Surgical Category & Upper Abdominal & Lower abdominal \\
\hline Colorectal & $\begin{array}{l}\text { Anterior resection } \\
\text { Abdominoperineal resection } \\
\text { Hartmanns } \\
\text { Hemicolectomy } \\
\text { Low anterior resection } \\
\text { Laparoscopic (+/-hand) assisted colectomy } \\
\text { Partial colectomy } \\
\text { Proctocolectomy } \\
\text { Reversal of Hartmanns } \\
\text { Sigmoid colectomy } \\
\text { Small bowel resection } \\
\text { Subtotal colectomy } \\
\text { Total colectomy }\end{array}$ & $\begin{array}{l}\text { Ultra low anterior resection } \\
\text { Recto-sigmoidectomy } \\
\text { Ileostomy } \\
\text { Appendectomy }\end{array}$ \\
\hline Upper Gastrointestinal & $\begin{array}{l}\text { Gastrectomy } \\
\text { Liver resection } \\
\text { Oesophagectomy } \\
\text { Open cholecystectomy } \\
\text { Open hiatus hernia repair } \\
\text { Pancreatic surgery } \\
\text { Whipples }\end{array}$ & \\
\hline Urology & $\begin{array}{l}\text { Adrenalectomy } \\
\text { Cystic duct excision } \\
\text { Nephrectomy } \\
\text { Laparoscopic +/- hand assisted nephrectomy } \\
\text { Pyeloplasty } \\
\text { Radical cystectomy +/- ileal conduit } \\
\text { Radical cystoprostatectomy }\end{array}$ & $\begin{array}{l}\text { Radical prostatectomy } \\
\text { Ureterectomy }\end{array}$ \\
\hline Other & $\begin{array}{l}\text { Explorative laparotomy } \\
\text { Splenectomy } \\
\text { Complete pelvic exenteration }\end{array}$ & $\begin{array}{l}\text { Inguinal hernia repair } \\
\text { Total abdominal hysterectomy }\end{array}$ \\
\hline
\end{tabular}

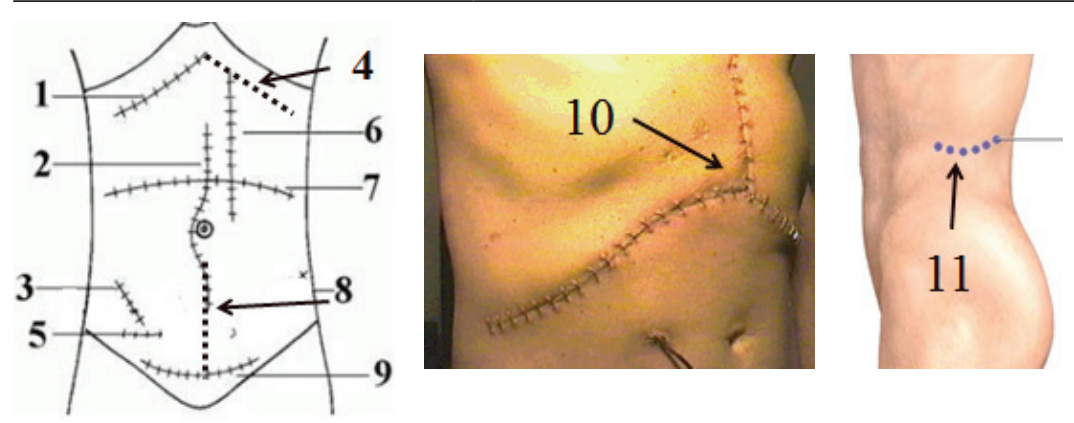

1. Subcostal (Kocher)

2. Midline laparotomy

3. McBurney

4. Bilateral subcostal (Chevron)

5. Lanz

6. Paramedian

7. Transverse

8. Lower midline

9. Pfannenstiel

10. Mercedes (Chevron + Sternotomy)

11. Flank/transverse lumbar
Liver and pancreas operations

Upper and lower intestinal procedures, major bladder

Appendix removal

Oseophageal, liver, pancreatic, and gastric procedures

Appendix removal

Upper gastrointestinal surgery

Upper intestinal procedures

Lower intestinal procedures and bladder

Major gynaecological and prostate procedures

Major trauma, combined cardiac and abdominal

Kidney procedures

Figure 1: Incisions used for abdominal surgery and associated procedures (Mercedes image: Said 2008) 


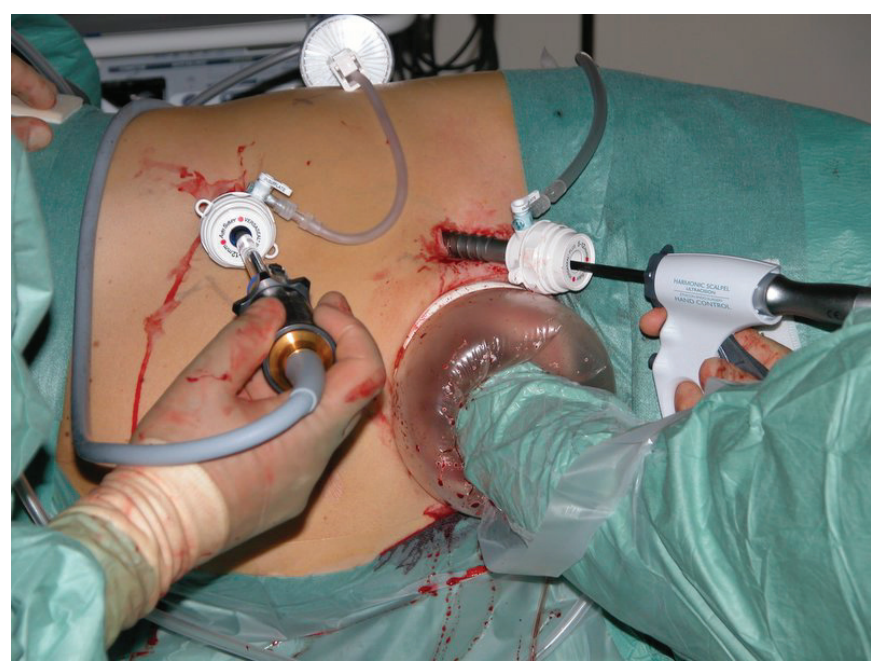

Figure 2: Laparoscopic hand-assisted abdominal surgery (Dols et al 2009)

Significant changes in perioperative care have also been initiated, most notably Enhanced Recovery after Surgery (ERAS) or 'fast track' pathways. Elements include minimal preoperative bowel preparation and fasting, admission on the day of surgery, aggressive early ambulation, strict analgesia protocols, early postoperative introduction of oral fluids and food, and minimal use of drips and drains. These pathways are safe, feasible and reduce complication rates and LOS across all types of abdominal surgery (Adamina et al 2011, Cerantola et al 2013, Coolsen et al 2013, Li et al 2012, Lin et al 2011, Varadhan et al 2010, Wijk et al 2014).
Prevention of postoperative complications relevant to physiotherapy

\section{Postoperative pulmonary complications (PPCS) \\ What are PPCs and how are they measured?}

A PPC is commonly described as "a pulmonary abnormality that produces identifiable disease or dysfunction, that is clinically significant and adversely affects the clinical course" (O'Donohue Jr 1992). This can include respiratory failure, pneumonia, severe atelectasis, pulmonary oedema, pneumothorax, and pleural effusion. A PPC is the most common complication following UAS (PROVHILO group 2014) with a reported incidence of 13-53\% (Browning et al 2007, Haines et al 2013, Mackay et al 2005, Parry et al 2014, Scholes et al 2009, Silva et al 2013). This is higher than other major surgical procedures, such as open lung resection, cardiac surgery via sternotomy, and orthopaedic surgery (Arozullah 2001, Pasquina and Walder 2003, Reeve et al 2010), whereas the PPC rate following open LAS is as little as 1\% (Arozullah 2001, Smith et al 2009a).

The wide range in reported PPC rates following UAS may be explained by the surgical procedures, patient populations studied, and the PPC diagnostic tool or criteria utilised.

Diagnosis of a PPC differs greatly between studies. Variations include the individual signs and symptoms required for diagnosis (e.g. some tools incorporate auscultation changes where others do not), how each criterion is measured (e.g. the different grading scales used for radiographic atelectasis or consolidation) and the threshold number of positive criteria equating to a PPC (Agostini et al 2011, Wynne 2004). These inconsistencies make comparison of PPC rates and interpretation of research findings into clinical practice problematic. Although there is no consensus on the ideal tool for PPC diagnosis, recent physiotherapy-led studies have used the same multi-factorial scoring tool, the Melbourne Group Score (Table 2) in both UAS (Browning et al

Table 2: Melbourne Group Score PPC Diagnostic Tool

Diagnosis confirmed when 4 or more of the following are present:

\section{CLINICAL FACTORS}

- New abnormal breath sounds on auscultation different to preoperative assessment

- Production of yellow or green sputum different to preoperative assessment

- Pulse oximetry oxygen saturation $\left(\mathrm{SpO}_{2}\right)<90 \%$ on room air on more than one consecutive postoperative day

- Raised maximum oral temperature $>38^{\circ} \mathrm{C}$ on more than one consecutive postoperative day

\section{DIAGNOSTIC FACTORS}

- Chest radiograph report of collapse/consolidation.

- An unexplained WCC greater than $11 \times 10^{9} / \mathrm{L}$

- Presence of infection on sputum culture report

\section{OTHER}

- Physician's diagnosis of pneumonia, respiratory tract infection, undefined respiratory problem.

- Prescription of an antibiotic for a respiratory infection

Notes: C, centigrade; L, litre; $\mathrm{SpO}_{2}$, Peripheral oxygen saturation; WCC, white cell count. 
2007, Haines et al 2013, Parry et al 2014, Scholes et al 2009) and thoracic surgery (Agostini et al 2013, Reeve et al 2010). Reliable clinometric properties for the Melbourne Group Score (MGS) are beginning to be demonstrated when compared to other PPC diagnostic tools (Agostini et al 2011). Studies using the MGS have reported PPC rates of $13-18 \%$ in all patients undergoing major UAS (Browning et al 2007, Scholes et al 2009), and specifically $39-42 \%$ in high-risk UAS patients (Haines et al 2013, Parry et al 2014).

Key Point:

For research, audit and clinical purposes, the use of the Melbourne Group Score tool is recommended to diagnose a PPC amenable to physiotherapy.

What are the consequences and costs of a PPC? Postoperative pulmonary complications significantly increase morbidity, mortality, hospital utilisation, cost, and length of hospital stay (Dimick et al 2004, Knechtle et al 2014, Lång et al 2001, Rotta et al 2013, Thompson et al 2006). The greatest proportion of hospital costs are associated with intensive care utilisation and hospital LOS (Knechtle et al 2014). Australian prospective observational studies measuring PPC rates using the MGS found that PPCs increased hospital LOS by 3-13 days (Denehy et al 2001, Scholes et al 2009). To date, reported costs associated with PPCs have been derived retrospectively from hospital clinical coding databases that often underreport rates of complications and costs (Koch et al 2012). The true costs of PPCs are important to establish so that the cost-effectiveness of prophylactic interventions, including physiotherapy, can be calculated. It may not be cost effective to provide physiotherapy to all patients undergoing abdominal surgery. Where the likelihood of developing a PPC is known to be low, e.g. one PPC in every 100 patients, providing prophylactic physiotherapy to all 100 patients may cost more than the costs saved through preventing the one PPC. However, if PPCs are shown to be high cost, the benefit of preventing one PPC in 100 patients may outweigh the cost of providing a relatively low-cost intervention such as physiotherapy to all 100 patients. Until we have contemporary high quality physiotherapy evidence and cost-benefit analyses, physiotherapists may be best to target interventions to those patients who are at high-risk of postoperative complications. It is therefore important that physiotherapists are able to determine which patients are most at risk of developing a PPC.

Key Point:

Cost-benefit analyses of physiotherapy interventions to reduce PPCs, improve recovery and reduce LOS are needed to inform resource allocation.

How can we predict who is at risk of developing a PPC? The ability to predict the development of a PPC has been widely investigated. An often cited large prospective cohort study ( $n=160,805)$ (Arozullah 2001) investigated all patients undergoing non-cardiac surgery and found that those undergoing UAS were almost three times more likely to develop pneumonia (OR 2.68, 95\% Cl 2.38-3.03) compared to LAS and orthopaedic surgery where the pneumonia rate was less than $1 \%$. A recent retrospective study found that PPCs were 15 times more likely following UAS when compared to LAS (Smith et al 2009a).

The incidence of PPCs after traditional laparoscopic surgery is also negligible (<1\%) (Antoniou et al 2014). However, pneumonia rates of $2-5 \%$ have recently been reported following minimally invasive bowel resections and, whilst this is half the rate of the equivalent open procedure, PPC incidence has been shown to increase by $13 \%$ with each additional 60 minutes of surgery time (Owen et al 2013). The risk of PPCs following other types of minimally invasive UAS is not well reported. Until more data and cost-benefit analyses of physiotherapy interventions are published, it is uncertain if these PPC rates are high enough to justify providing routine prophylactic physiotherapy to these lower-risk patients.

To assist in directing physiotherapy resources to the highest need patients, PPC risk prediction tools should be utilised. Most PPC risk prediction tools following UAS have been developed by medical researchers (Barnett and Moonesinghe 2011) and have limited clinical utility for physiotherapists. To address this a physiotherapist led prospective study (Scholes et al 2009) investigated predictors for PPCs (with MGS diagnosis) to enable the development of a multifactorial scoring tool to dichotomise patients having UAS into high or low risk groups. Independent predictors of PPCs were: anaesthesia longer than three hours, upper gastrointestinal surgery, current smoking history, respiratory disease and estimated $V^{2 m a x}$. High-risk patients were 8.5 times more likely to develop a PPC than those assessed as low-risk. Other physiotherapy studies have found additional independent risk factors for a PPC. A nasogastric tube (Parry et al 2013) for more than one day was associated with higher PPC incidence (OR 9.1, 95\% CI 2.0 to 42) and delayed time to ambulate more than 10 metres (Haines et al 2013) was three times more likely to be related to the presence of a PPC (OR 3, 95\% CI 1.2 to 8). These results should be interpreted with caution, as it is possible that the presence of a PPC delayed mobilisation, rather than vice versa. The use of available PPC risk prediction models to target provision of physiotherapy services to higher-risk patients may be a prudent use of finite physiotherapy resources.

Key Points:

1. Patients following LAS and standard laparoscopic surgery do not require routine postoperative physiotherapy to prevent PPC.

2. All patients undergoing UAS should be screened for risk of developing a PPC using a risk identification tool and those patients determined to be high-risk are targeted with PPC prophylaxis.

3. A PPC risk prediction tool is needed for advanced laparoscopic and minimally invasive UAS.

Complications associated with reduced or delayed mobility

Venous thromboembolism

The absolute risk of venous thromboembolic events (VTE) after major abdominal surgery without preventative measures is approximately $15-40 \%$ (Cayley 2007). Given the serious 
consequences of pulmonary emboli (PE), several guidelines for prevention and management have been published by the American College of Chest Physicians (Holbrook et al 2012), Scottish Intercollegiate Guidelines Network (SIGN 2010) and the National Institute for Health and Clinical Excellence (National Institute for Health and Clinical Excellence (NICE) 2010). These guidelines recommend that all major surgical patients have VTE prophylaxis, including anti-coagulation and early mobilisation. If a deep vein thrombosis (DVT) is diagnosed and anti-coagulation has been commenced, early mobilisation is not associated with increased risk of PE, new DVT or death (Aissaoui et al 2009, Anderson et al 2009), thus physiotherapists should recommence active ambulation following medical clearance.

\section{Postoperative paralytic ileus}

Gut immotility immediately postoperatively is an expected consequence of abdominal surgery (Vather et al 2013). There is a widespread belief that early ambulation assists in the resolution of gut immotility and prevention of paralytic ileus, yet there is no conclusive evidence to support this hypothesis (Story and Chamberlain 2009). Indeed, there is stronger evidence for the routine use of chewing gum, which stimulates the neurohormonal response to eating and enhances the resolution of a normal gut peristalsis, to prevent paralytic ileus and reduce LOS (Li et al 2013), than there is for early ambulation.

\section{Musculoskeletal and cardiovascular effects}

Whilst early ambulation is recommended following major abdominal surgery, surgical drains/devices and the postoperative sequelae of hypotension, nausea, pain, and fatigue mean that achieving early ambulation as recommended is frequently not achieved (Haines 2013, Boulind 2012). Although the deleterious musculoskeletal and cardiovascular effects associated with prolonged bedrest are well documented (Pavy-Le Traon et al 2007), there is little evidence to support the use of early ambulation in the prevention of PPCs. A recent randomised controlled trial (RCT) found no increase in PPC incidence following three days enforced bed rest; rather this group had prolonged LOS and required more physical rehabilitation to assist recovery (Silva 2014).

\section{Physiotherapy management for patients undergoing} abdominal surgery

Physiotherapy aims to address well-known pathophysiological effects of abdominal surgery on the respiratory system including atelectasis (Duggan and Kavanagh 2005, Hedenstierna and Edmark 2010, Tusman et al 2012), reduced muco-ciliary clearance (Bilgi et al 2011, Gamsu et al 1976, Konrad et al 1993), diaphragm dysfunction (Blaney and Sawyer 1997, Ford et al 1983, Kim et al 2010), reduced lung volumes (Cheifetz et al 2010, Fagevik Olsén et al 2009, Stock et al 1985) and reduced respiratory muscle and cough strength (Barbalho-Moulim et al 2011, Bellinetti and Thomson 2006, Kulkarni et al 2010). It is hypothesised that combinations of these factors can lead to bacterial proliferation in the airways and/or severe atelectasis (Smith and Ellis 2000), increasing the risk of infection and PPCs.

It is a logical assumption that strategies to ameliorate the deleterious physiological effects of abdominal surgery will result in reducing the risk of PPC development. This has been the underlying premise of the delivery of 'chest physiotherapy' to patients following major surgery for several decades. Physiotherapy may consist of preoperative education and training and/or postoperative respiratory and physical rehabilitation. More recently, there has been an increasing focus on preoperative exercise training (prehabilitation). Here we present the best available evidence to guide practice decisions.

\section{Preoperative physiotherapy interventions \\ Preoperative education}

Preoperative physiotherapy education is the delivery of targeted preparatory information to the patient regarding the expected postoperative participation in an early ambulation programme and necessity to perform deep breathing and coughing (DB\&C) exercises. Patients are educated on the role these exercises have on the reduction of serious complications such as PPC and VTEs. Sessions consist of explaining the effect of anaesthesia and surgery on the lungs, teaching and training of DB\&C exercises, education on the early ambulation programme and provision of any adjunctive devices as necessary.

Evidence from six clinical trials (Bourn et al 1991, Castillo and Haas 1985, Condie et al 1993, Denehy 2001, Fagevik Olsén et al 1997, Samnani et al 2014) suggests that a single preoperative physiotherapy session significantly reduces PPC rates. In the largest RCT ( $n=368$, PEDro 5/10) the intervention group received a single preoperative physiotherapy education and training session and a single postoperative review of taught breathing exercises (Fagevik Olsén et al 1997). The control group received no pre or postoperative physiotherapy. The incidence of PPC was significantly lower in the treatment group (6\% vs $27 \%$, $\mathrm{p}<0.001)$. Two other RCTs of 330 low-risk open abdominal surgery (Condie et al 1993) and 102 open UAS patients (Denehy 2001) concluded that the provision of additional postoperative physiotherapy of coached DB\&C exercises conferred no extra benefit over and above a single session of preoperative education and DB\&C training alone. A recent RCT (Samnani et al 2014) of 232 abdominal surgery patients again demonstrated a significant reduction in PPCs from 30\% to 7\% (ARR 22\%, $95 \% \mathrm{Cl} 13 \%-32 \%$ ) when preoperative education focused on the importance of postoperative early ambulation compared to no education at all. Both groups were provided with similar postoperative care. These studies demonstrate the effectiveness of preoperative education and DB\&C training, independent of postoperative physiotherapy, in reducing the incidence of PPCs.

The reported reduction in PPCs with preoperative physiotherapy education is significant; however, the results need to be interpreted with caution. All trials had methodological limitations and sources of bias. This brings the reported effect on PPC rates into question. Further, most trials were conducted 10-15 years ago and there have been significant changes in surgical and perioperative care in this time. Preoperative education and training have previously been provided the day before surgery upon admission for surgery, however this no longer reflects current practice, whereby patients attend preoperative assessment clinics one to six weeks before their operation (Gupta and Gupta 2010). It is unknown whether preoperative physiotherapy education provided at these longer time intervals might reproduce the previously reported effect on PPC prophylaxis. 
Surveys of physiotherapy services to UAS patients in Australia have shown a stark reduction in hospitals providing preoperative physiotherapy education over the past 15 years (Browning 2007, Scholes et al 2006). The reasons for this disinvestment of services are unknown. There are no cost-benefit analysis studies investigating physiotherapy to reduce respiratory complications, so conclusive evidence to inform the allocation of physiotherapy services to preoperative education and training is lacking. The potential to significantly reduce the incidence of a high-impact complication, such as a PPC, with a low-cost and easily provided intervention of a single preoperative physiotherapy session is appealing. It may not be how much physiotherapy that is important, but rather, when that physiotherapy is provided. The current weight of evidence appears to support the provision of a single preoperative physiotherapy education and DB\&C training to all patients having abdominal surgery (Bourn et al 1991, Condie et al 1993, Denehy 2001, Fagevik Olsén et al 1997, Samnani et al 2014). Given the limitations of this research and the low incidence of PPCs following laparoscopic and LAS surgery, the authors recommend the provision of preoperative physiotherapy for all open UAS patients only. Cost benefit studies are required to analyse the fiscal benefits of providing preoperative physiotherapy to lower risk surgical patients as well.

Key Points:

1. A single face to face session of preoperative education and DB\&C training should be administered to all patients undergoing open upper abdominal surgery.

2. It is currently unknown if other forms of this education and training, eg video or booklet, are effective.

\section{Prehabilitation}

Prehabilitation refers to the use of exercise-based interventions aimed at optimising preoperative function to improve postoperative outcomes or to increase surgical options in those patients who have borderline fitness for surgery. Evidence of the effectiveness of prehabilitation is relatively new, yet systematic reviews and meta-analyses have already been undertaken (Lemanu et al 2013, Olsén and Anzén 2012, Singh et al 2013, Valkenet et al 2011), although only two focused solely on major abdominal surgery (Pouwels et al 2014, Pouwels et al 2015).

Valkenet et al (2011) and Santa Mina (2014) conducted metaanalyses on the effects of preoperative interventions including inspiratory muscle training (IMT) and/or exercise training in patients undergoing major cavity and orthopaedic surgery. Mans et al (2015) investigated IMT prior to all types of open major cavity surgery, including UAS. Meta-analyses of the data demonstrated significant reduction in the risk of PPCs (Mans et al 2015, Valkenet et al 2011) and reduced postoperative length of stay (Santa Mina et al 2014, Valkenet et al 2011). Other systematic reviews report improvements in aerobic and functional capacity (Lemanu et al 2013, Olsén and Anzén 2012, Singh et al 2013). These reviews are limited by the lack of meta-analysis due to the small number of studies included and the heterogeneity of the surgical groups, which included combinations of orthopaedic, UAS, cardiac and thoracic surgery.

To our knowledge, there are only two systematic reviews specifically relating to prehabilitation in abdominal surgery
(Pouwels et al 2014, Pouwels et al 2015). These two reviews detailed six RCTs in both laparoscopic and open abdominal surgery (Pouwels et al 2014) and five studies in abdominal aortic aneurysm repair specifically (Pouwels et al 2015). Studies investigated strength and/or aerobic training, breathing exercises, education and IMT or combinations of these. The heterogeneity of the investigations precluded meta-analyses as studies utilised a variety of frequencies, intensities, durations, modes, locations and outcome measures. Both reviews (Pouwels et al 2014, Pouwels et al 2015) determined that preoperative exercise therapy is associated with improved physical fitness in patients prior to major abdominal surgery, but, due to heterogeneity and small sample sizes, whether this results in fewer complications or faster recovery remains unclear. Although the relationship between poor preoperative fitness and postoperative outcomes has been clearly demonstrated (Smith et al 2009b), the effect of improving fitness (via prehabilitation) and improved postoperative outcomes is yet to be demonstrated. Better quality, targeted research into preoperative physical fitness optimisation, particularly in highrisk patients, is warranted.

\section{Key Point:}

Given the small number of studies, the heterogeneity of interventions and costs involved in providing such services, the routine provision of prehabilitation in all patients undergoing abdominal surgery cannot be recommended. However, it may be worthwhile in high-risk UAS patients, given the assumed cost of complications. This remains to be confirmed with cost-benefit studies.

\section{Postoperative physiotherapy interventions \\ Postoperative ambulation}

Early mobilisation forms a routine part of postoperative care and physiotherapists are heavily involved in the initiation of mobilisation following UAS, with up to $91 \%$ reporting they always include mobilisation in their postoperative treatment (Browning 2007). Patients perform little mobilisation outside of physiotherapy treatment in the early postoperative period (Browning et al 2007) with one study demonstrating only $48 \%$ of patients mobilised more than $10 \mathrm{~m}$ on the first postoperative day (Haines et al 2013). To address this, aggressive early ambulation protocols have become an essential component of ERAS guidelines whereby patients sit up out of bed for six to eight hours and ambulate at least $60 \mathrm{~m}$ up to five times on the day after surgery (Delaney et al 2001). However only $40 \%$ of patients are able to achieve this (Boulind et al 2012). Studies investigating adherence to ERAS protocols found the early mobilisation component was the least adhered to (Boulind et al 2012, Gustafsson et al 2011). Barriers to achieving early ambulation include hypotension, pain and nausea (Haines et al 2013).

Research into the efficacy of physiotherapy to improve outcomes following abdominal surgery has almost always involved ambulation as part of an intervention package (e.g. preoperative education, DB\&C exercises, early ambulation, adjunctive devices). It is difficult to determine which component of the intervention is responsible for any improvements in outcomes. 
Only two studies have attempted to specifically isolate the effect of DB\&C from standardised early ambulation. Mackay et al (2005) compared PPC rates in 56 patients randomised to an ambulation only group or a group provided with additional supervised DB\&C exercises; of note the protocol for both groups was intensive, with three ambulation sessions on the first and second postoperative day and continuing twice daily for the next two days. The overall PPC rate was $14 \%$ with no significant difference between groups. A similar study replicated this protocol with a more realistic ambulation protocol. Silva et al (2013) randomised 86 high-risk UAS patients into three groups: mobilisation alone, mobilisation plus DB\&C, and delayed mobilisation (commenced on the third postoperative day) plus DB\&C. Participants were ambulated once daily to a BORG intensity of $6 / 10$. There were no significant differences in PPC rate between groups even in the group that rested in bed for three days; although this group were no more likely to get a PPC, they had increased requirements for physiotherapy to assist in their physical recovery and significantly longer LOS (MD 4.4, 95\% Cl 0.3 to 8.8). Both of these studies suggest that the addition of DB\&C to early ambulation does not reduce the incidence of PPC. However, it is important to note that these studies were not powered to measure small to moderate differences in PPC rates (less than 20\% between groups). It is possible that coached DB\&C exercises could provide a small, yet clinically worthwhile effect. Much larger clinical trials would need to be performed to test this.

\section{Key Points:}

1. Because of the undesirable sequelae associated with prolonged bedrest, ambulation should be commenced as early as safely possible for all patients undergoing all types of abdominal surgery.

2. There is little evidence to support the use of early ambulation in the prevention of PPCs.

3. The ideal amount, duration, and frequency, of ambulation required to improve postoperative recovery is untested.

Postoperative breathing exercises.

Coached DB\&C exercises are traditionally provided to patients following UAS aiming to prevent PPCs. Incentive spirometers (IS) (do Nascimento Junior et al 2014), PEP devices (Orman and Westerdahl 2010, Zhang et al 2015), and non-invasive ventilation (NIV) (Ferreyra et al 2008) are also utilised, but less frequently. These modalities are often delivered by physiotherapists (Haines et al 2013, Makhabah et al 2013), although in some countries these may be provided by other health professionals (Cassidy et al 2013, Zhang et al 2015). Despite widespread and ubiquitous provision of prophylactic respiratory physiotherapy following abdominal surgery, its efficacy and worth in preventing PPCs is unclear.

Two systematic reviews have investigated interventions to prevent PPCs following abdominal surgery (Lawrence et al 2006, Pasquina et al 2006). Despite being conducted in the same year, the conclusions were contradictory. Lawrence et al (2006) investigated all non-pharmaceutical interventions to prevent respiratory complications including a wide range of interventions (such as nasogastric decompression, postoperative analgesia) in open, laparoscopic, LAS and UAS. Findings suggested there is good evidence for any type of lung expansion manoeuvres compared with no treatment at all but that studies were confounded by the use of multimodal interventions, inconsistent definitions of PPC and poor methodologies. Pasquina et al (2006), in a robust and detailed systematic review, focused solely on physiotherapy interventions and meta-analysed 35 studies conducted in both LAS and UAS. Less than half of all trials found that $D B \& C$ exercises were more effective than a no-treatment control or alternative technique. They concluded that the routine use of respiratory physiotherapy after open abdominal surgery is not justified.

Since the 2006 publication of these systematic reviews (Lawrence et al 2006, Pasquina et al 2006), seven additional RCTs have been published (Baltieri et al 2014, Barbalho-Moulim et al 2011, Dronkers 2008, Kulkarni et al 2010, Samnani et al 2014, Silva et al 2013, Zhang et al 2015). The findings of these further studies are summarised in Table 3 and the results and context of the findings are discussed elsewhere in this paper where appropriate. The methodological quality of each of these trials has been assessed using the PEDro scale and absolute risk reduction (including confidence intervals) and number needed to treat have been calculated from the dichotomous PPC data supplied in the studies where possible.

One further systematic review assessed specifically the effect of breathing exercises on physiological aspects of pulmonary function following abdominal surgery such as respiratory muscle strength and diaphragm mobility (Grams et al 2012). This study and others (Grams et al 2012, Lunardi et al 2013, Lunardi et al 2015) have demonstrated that DB\&C improve respiratory function following UAS, although it remains unclear whether these physiological improvements translate to clinically meaningful reductions in LOS or incidence of PPCS.

In the face of contradictory evidence for the use of DB\&C exercises, an international panel of experts have attempted to provide a consensus statement on physiotherapy management for patients following UAS (Hanekom et al 2012). Using the Grades of Recommendation, Assessment, Development and Evaluation (GRADE) approach (Guyatt et al 2008), the panel considered the potential benefits of coached DB\&C exercises outweighs the potential costs and harms of the intervention. Until this is confirmed with further high-quality evidence and cost-benefit analysis this recommendation remains supported by a weak level of evidence.

Regarding laparoscopic and LAS, although respiratory physiotherapy demonstrates physiological improvements in pulmonary function (Forti et al 2009, Gastaldi et al 2008, Krishna et al 2013), the PPC rate is very low (Arozullah et al 2000, Condie et al 1993) and postoperative respiratory physiotherapy for this population has not been shown to alter clinical outcomes such as incidence of PPC and LOS. However, with the increasing use of advanced technology, more complex surgeries are now being performed laparoscopically. Due to their complexity, the average time of these type of laparoscopic operations are usually greater than three hours (Fagevik Olsen M 1999, Kuo et al 2013, Park et al 2011). In these studies, the 
PPC incidence between open and laparoscopic surgery is similar, suggesting that there may be an increased PPC risk in prolonged laparoscopic surgery (Kuo et al 2013, Park et al 2011). This needs to be confirmed with prospective observational studies to enable risk prediction models to be developed, which will in turn assist physiotherapists and hospitals to determine which patients require targeted PPC prophylaxis following these newer types of procedures. To date, no study has investigated the effectiveness of any type of respiratory therapy to treat a PPC following diagnosis and this requires urgent investigation.

\section{Key Points:}

1. DB\&C exercises should not be provided routinely following LAS, standard laparoscopic surgery or for patients screened as being at low-risk of a PPC following UAS.

2. For high-risk UAS patients, on balance of the available evidence, the provision of coached DB\&C exercises may be unnecessary as long as patients are provided with an early ambulation programme of assisted walking at least once a day. It is suggested this assisted walking targets a BORG score $>6 / 10$.

\section{Respiratory adjuncts}

Systematic reviews and meta-analyses (do Nascimento Junior et al 2014, Overend et al 2001) have investigated the use of incentive spirometry (IS) for patients following abdominal surgery. In the most recent meta-analysis, do Nascimento Junior et al (2014) investigated 12 studies with a total of 1834 participants undergoing UAS including laparoscopic surgery. Trials compared IS to either no respiratory treatment; DB\&C; or to other types of chest physiotherapy. There were no statistically significant differences between any groups in the risk of developing a pulmonary condition. There are limitations with this literature due to mixed patient populations in some studies (UAS, LAS, laparoscopic) and due to varying risk profiles of patients. These limitations and the generally low quality of the evidence regarding the lack of effectiveness of IS in preventing PPCs following UAS highlight the need to conduct welldesigned trials in this field. Recently there has been a renewed interest in investigating IS in high-risk populations. For example, a pre-post cohort study in patients undergoing high-risk UAS has shown promising results (Westwood et al 2007) and these results now need to be tested in a RCT.

Only one systematic review has investigated the use of PEP devices (including bubble PEP) in patients undergoing open abdominal or thoracic surgery (Orman and Westerdahl 2010). The review found weak evidence that PEP confers any benefit over standard respiratory physiotherapy but due to the age and limited quality of the included studies (PEDro $4-6$ ), firm conclusions are unable to be drawn. A recent well-designed RCT (PEDro 8/10) compared routine medical management and early mobilisation with the use of modified oscillating PEP in 203 patients following UAS and thoracic surgery (see Table 3 for details) (Zhang et al 2015). The study found a significant reduction in days of fever and LOS in the PEP group (MD-2.6, $95 \% \mathrm{Cl}-4.8$ to -0.4$)$. The use of postoperative (oscillatory) PEP now requires further corroboration with studies in other countries and other surgical contexts, utilising outcome measures that include PPC incidence.

Two meta-analyses have compared prophylactic continuous positive airways pressure (CPAP), to prevent postoperative morbidity and mortality in patients following major abdominal surgery, with standard care (including physiotherapy) (Ferreyra et al 2008, Ireland et al 2014). Whilst no differences were found in the effects of CPAP on mortality and hypoxaemia, both studies showed significant reductions in atelectasis, pneumonia and reintubation rate with CPAP. Caution is required in extrapolating these results as the included studies had substantial heterogeneity, small sample sizes and a number were old with poor methodological reporting. There is evidence to suggest that CPAP and NIV are both effective in improving outcomes in patients who have developed postoperative respiratory failure although this is based on a small number of studies (Antonelli et al 2000, Chiumello et al 2011, Kindgen-Milles et al 2005).

\section{Other adjuncts}

The use of an abdominal binder, a firm removable elastic girdle placed around the abdomen, is popular in some countries following abdominal surgery in attempting to prevent wound dehiscence and improve postoperative pain and respiratory function (Bouvier et al 2014). Its use has shown improvements in postoperative walking distance following major UAS (Cheifetz et al 2010), but only weak effects on reducing pain (Rothman et al 2014) and no effect on pulmonary function or seroma formation (Fagevik Olsén et al 2009, Larson et al 2009, Rothman et al 2014) or LOS (Larson et al 2009). There is some evidence to suggest that abdominal binders improve psychological distress in the early postoperative period (Rothman et al 2014). Its use has yet to be related to PPC rates but evidence suggests that binders can be worn without compromising pulmonary function (Rothman et al 2014).

\section{Key Points:}

1. Incentive spirometry should not be routinely provided following abdominal surgery.

2. The use of oscillatory PEP may assist in preventing PPCS.

3. Postoperative prophylactic CPAP/NIV is efficacious in the prevention of PPCs, although evidence is insufficient on the potential for harm and the cost implications of providing CPAP/NIV prophylactically to all patients following UAS need to be considered.

\section{Post-discharge rehabilitation}

Health-related quality of life (HRQoL) has become an important end-point in the abdominal surgical literature. Delayed recovery and persistent disability following UAS has been demonstrated up to six months postoperatively (Lawrence et al 2004), with complications in the immediate postoperative period being independent predictors of poorer recovery and poor $\mathrm{HRQOL}$ (Davies et al 2013, Lawrence et al 2004). It is unknown if delays in functional recovery (or functional decline) following UAS are related to increased health utilisation costs, morbidity and mortality or if postoperative rehabilitation programmes would hasten recovery and reduce disability. To our knowledge, there are currently no studies investigating the impact of 
postoperative rehabilitation specifically for patients having undergone UAS. There is, however, a plethora of emerging literature demonstrating positive health benefits (including disease-free survival) at all stages of treatment in cancer survivors. Given that patients with cancer frequently present for abdominal surgery, and the known delayed recovery from UAS in some patients, the value of post-discharge rehabilitation for patients following UAS warrants further exploration.

Key Point:

In the absence of any evidence regarding postoperative rehabilitation programmes we are unable to make any recommendations regarding post-discharge physiotherapy.

\section{CONCLUSION}

The research regarding physiotherapy in the perioperative period for patients undergoing abdominal surgery is limited and equivocal. Physiotherapy services rely not only on the balance of evidence but on the balance of resources to provide these services. It is feasible that the potential high cost of PPCs following abdominal surgery justifies the provision of lowcost interventions such as physiotherapy. Until this has been confirmed with good quality research and cost analysis studies, physiotherapists should provide a service based on the best available evidence. This study has attempted to summarise such evidence, highlight the areas required for further research and make balanced recommendations for practice on the basis of these factors.

\section{DISCLOSURES}

No financial support was received in the preparation of this paper.

\section{ADDRESS FOR CORRESPONDENCE}

Julie C Reeve, School of Clinical Sciences, Faculty of Health and Environmental Studies, AUT University, Auckland, New Zealand. Email: julie.reeve@aut.ac.nz 


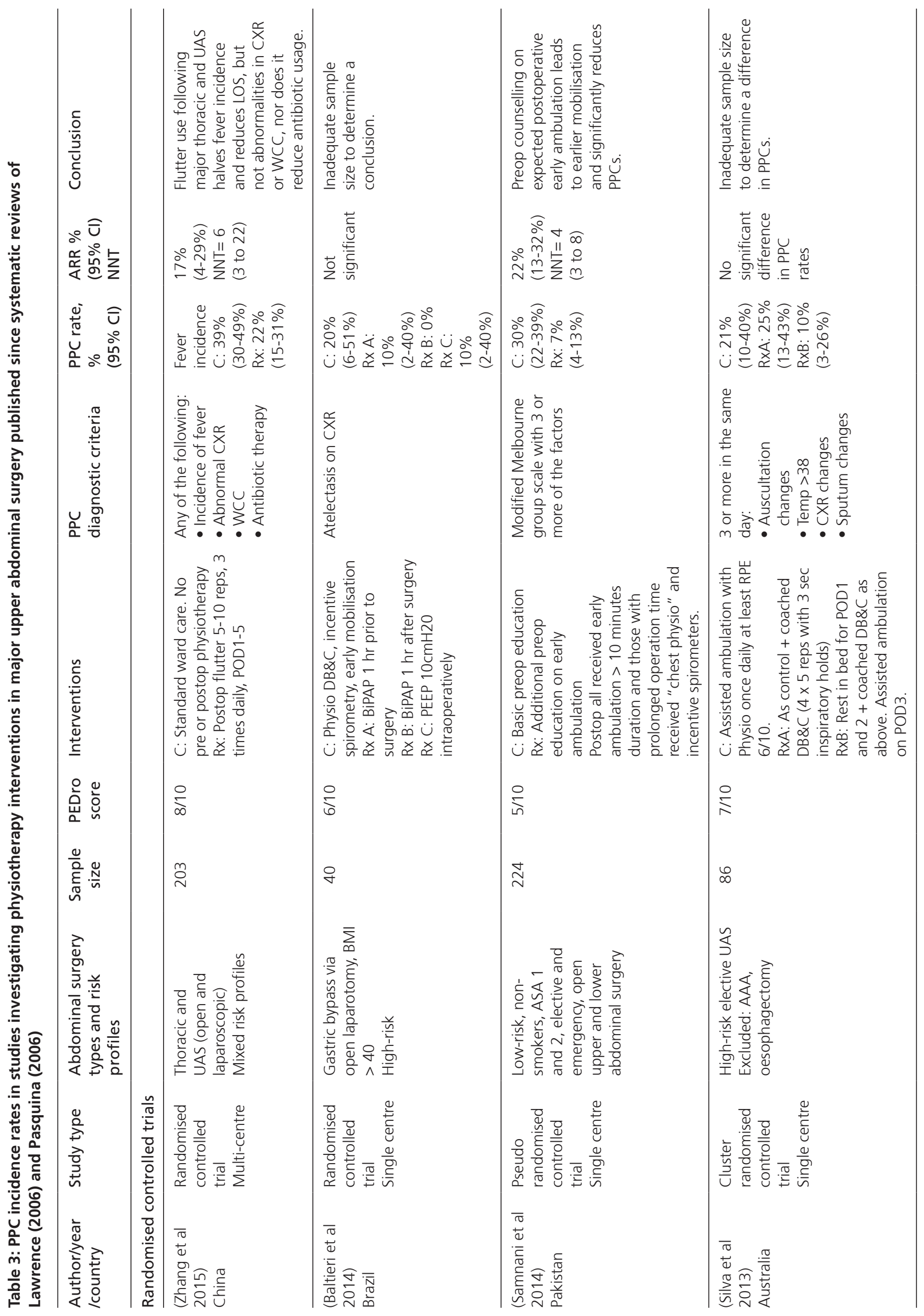




\begin{tabular}{|c|c|c|c|c|c|}
\hline 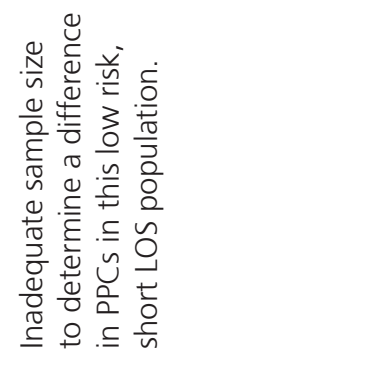 & 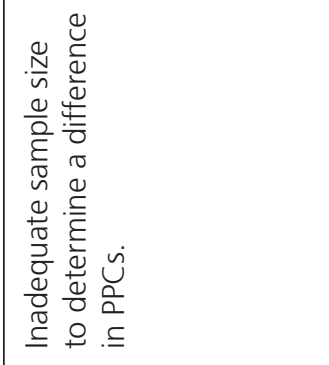 & 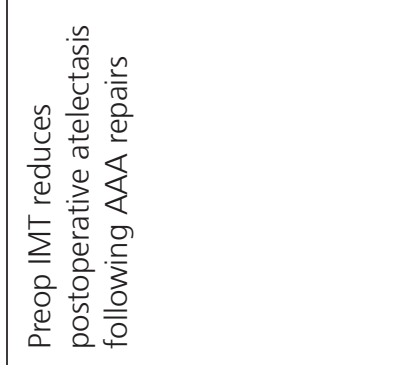 & & 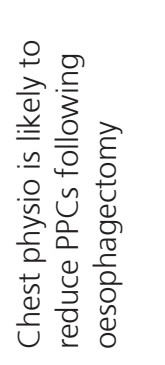 & 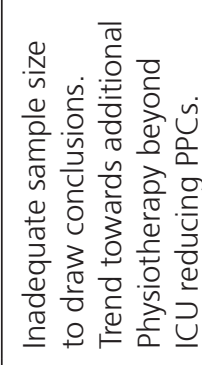 \\
\hline$\stackrel{\pi}{\varrho}$ & $\stackrel{\sim}{\stackrel{\sim}{n}}$ & 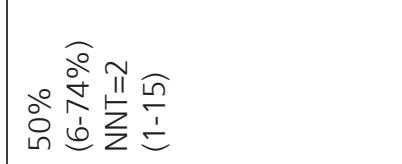 & & 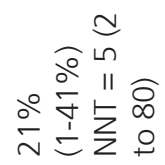 & 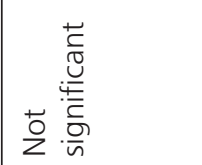 \\
\hline ஃ̊ & 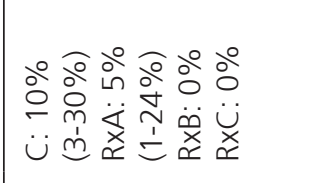 & 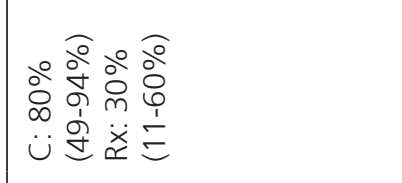 & & 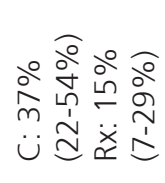 & 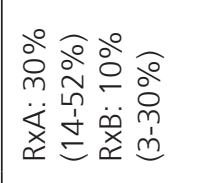 \\
\hline 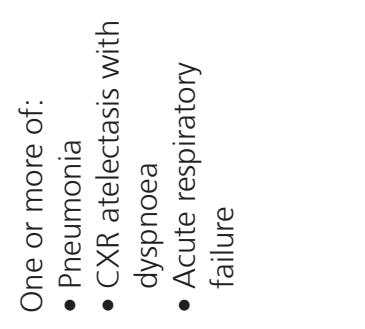 & 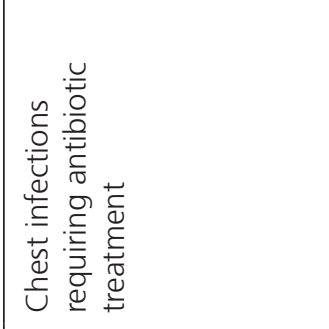 & 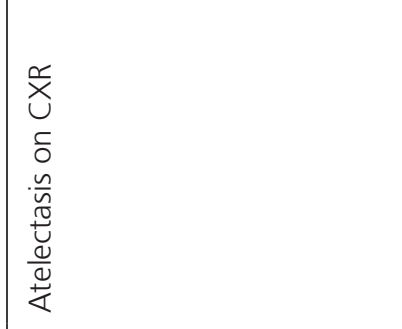 & & 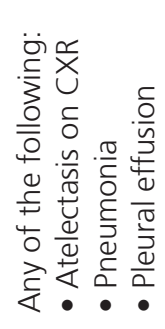 & 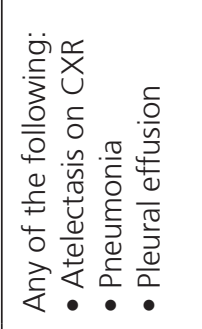 \\
\hline 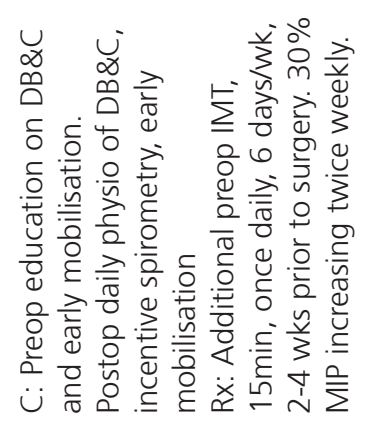 & 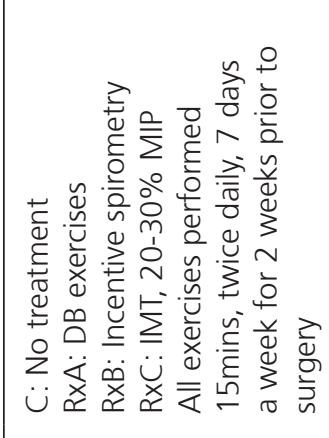 & 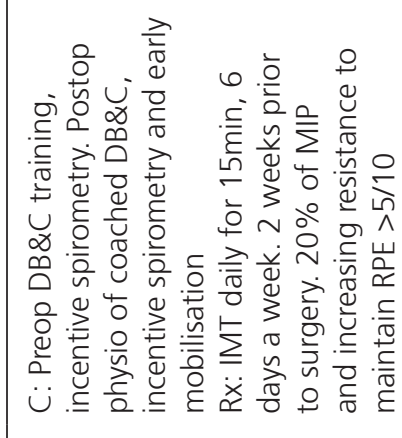 & & 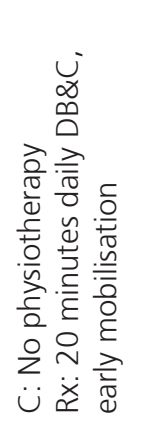 & 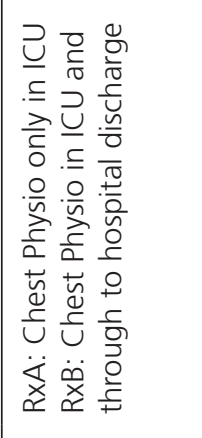 \\
\hline 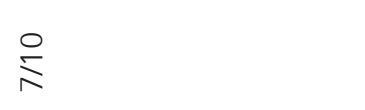 & 온 & $\stackrel{\circ}{\stackrel{2}{2}}$ & & & $\stackrel{\pi}{巳}$ \\
\hline$\tilde{m}$ & $\infty$ & i & & 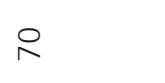 & q \\
\hline 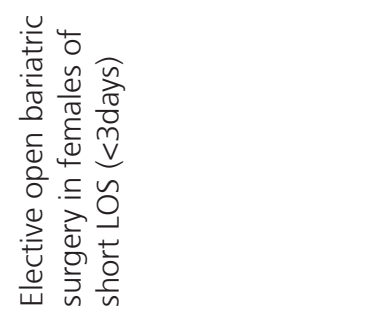 & 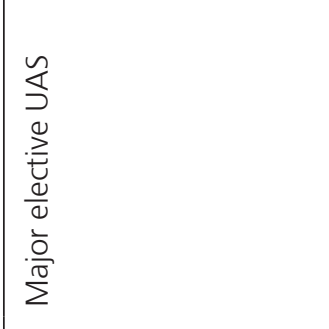 & 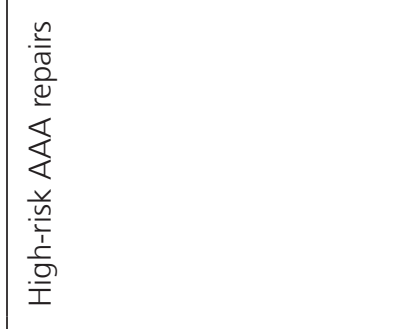 & & 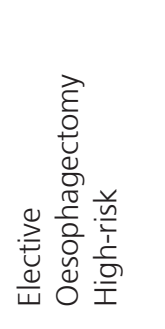 & 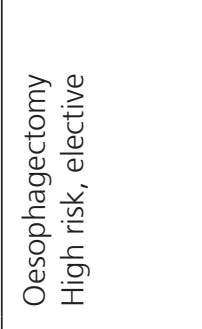 \\
\hline 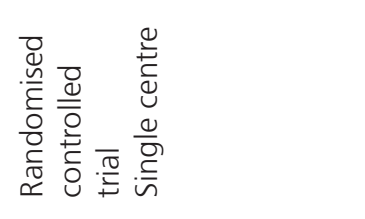 & 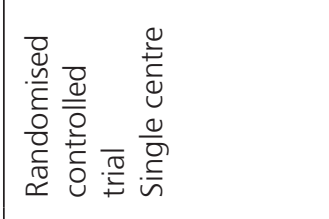 & 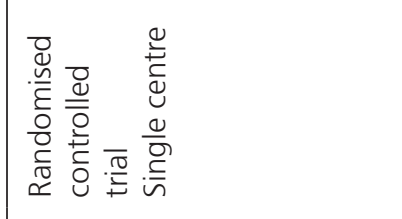 & 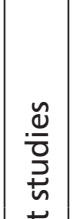 & 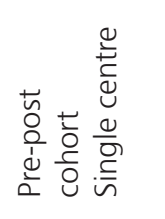 & 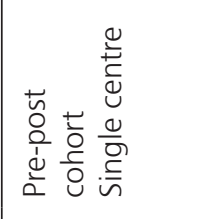 \\
\hline 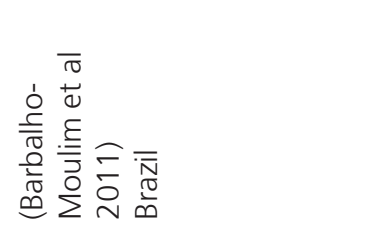 & 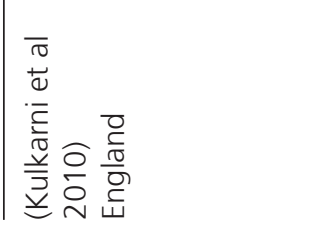 & 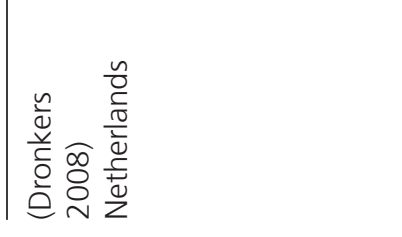 & 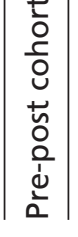 & 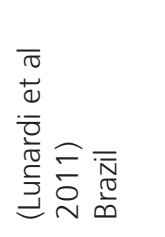 & 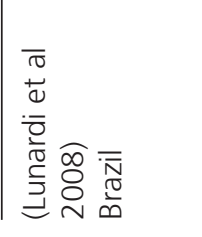 \\
\hline
\end{tabular}




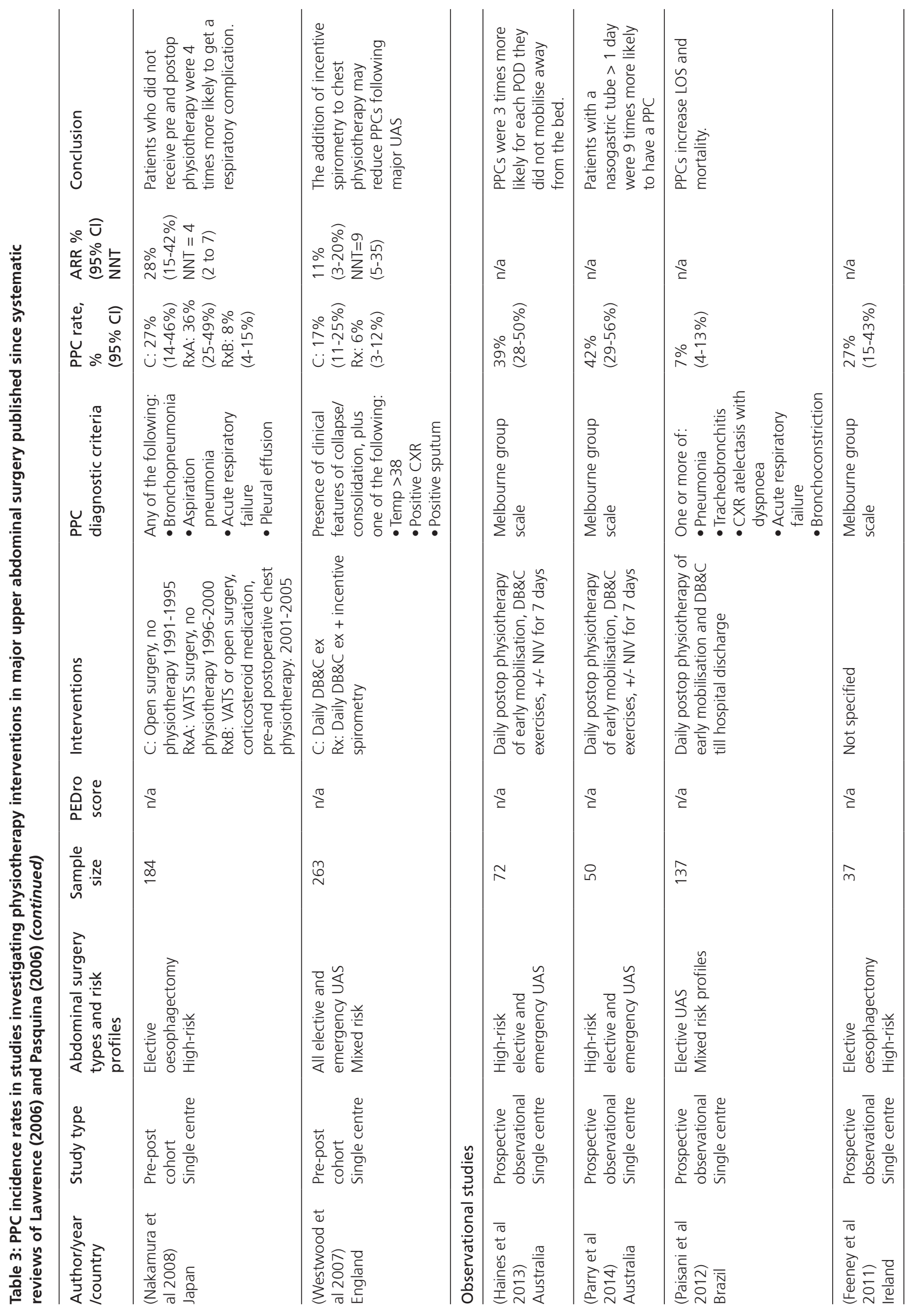




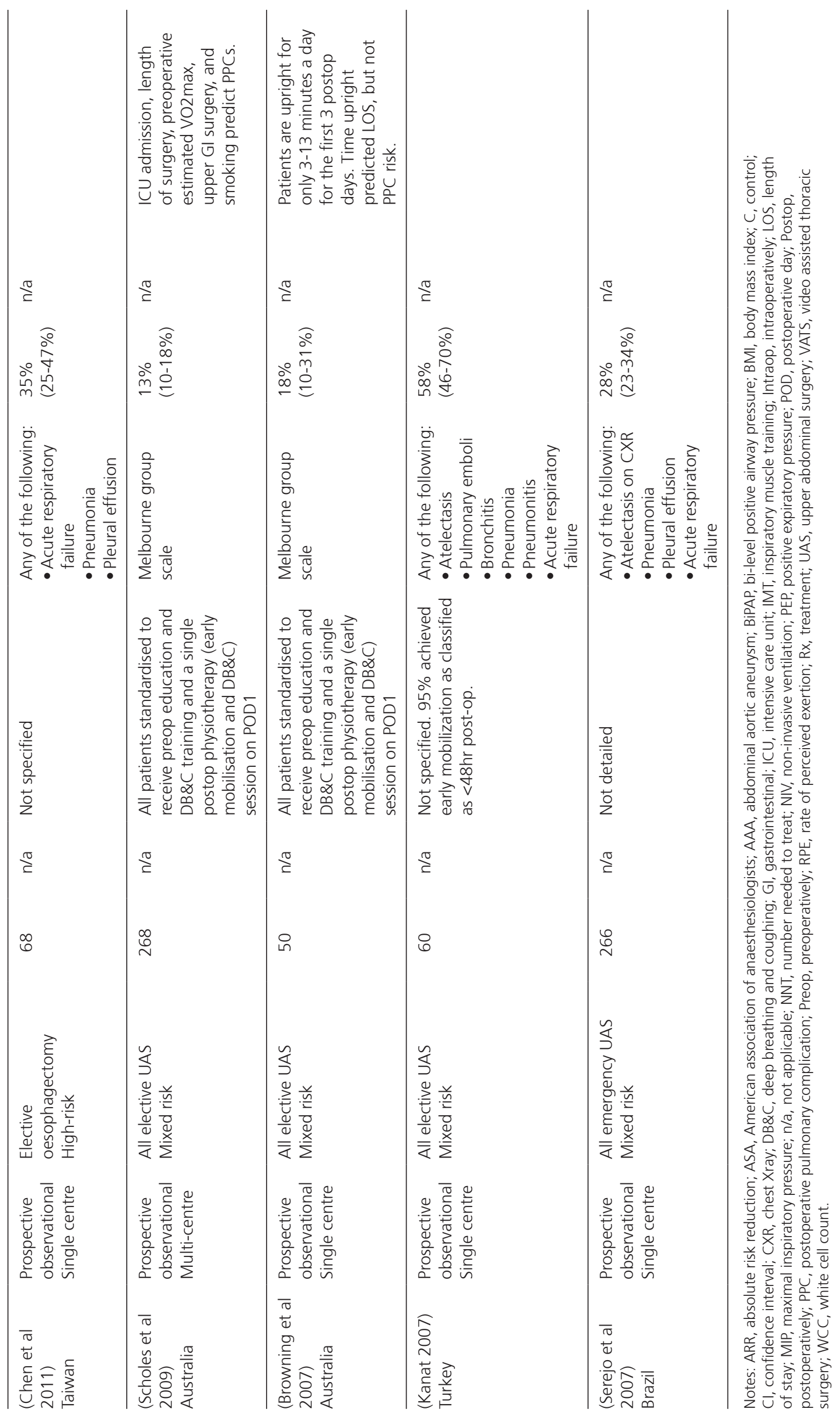




\section{REFERENCES}

Aahlin E, Tranø G, Johns N, Horn A, Søreide J, Fearon K, Revhaug A, Lassen K (2015) Risk factors, complications and survival after upper abdominal surgery: a prospective cohort study. BMC Surgery 15(1): 83. doi:10.1186/ s12893-015-0069-2

Adamina M, Kehlet H, Tomlinson GA, Senagore AJ, Delaney CP (2011) Enhanced recovery pathways optimize health outcomes and resource utilization: a meta-analysis of randomized controlled trials in colorectal surgery. Surgery 149(6): 830-840. doi:10.1016/j.surg.2010.11.003.

Agostini P, Naidu B, Cieslik H, Rathinam S, Bishay E, Kalkat M, Rajesh PB, Steyn R, Singh S (2011) Comparison of recognition tools for postoperative pulmonary complications following thoracotomy. Physiotherapy 97(4): 278-283. doi:10.1016/j.physio.2010.11.007.

Agostini P, Naidu B, Cieslik H, Steyn R, Rajesh PB, Bishay E, Kalkat MS, Singh $S$ (2013) Effectiveness of incentive spirometry in patients following thoracotomy and lung resection including those at high risk for developing pulmonary complications. Thorax 68(6): 580-585. doi:10.1136/ thoraxjnl-2012-202785

AlHW (2013) Procedures Cubes 2011-2012: National Hospital Morbidity Database. http://www.aihw.gov.au/hospitals-data/procedures-datacubes/\#ardrglink [Accessed 7/9/2014]

Aissaoui N, Martins E, Mouly S, Weber S, Meune C (2009) A meta-analysis of bed rest versus early ambulation in the management of pulmonary embolism, deep vein thrombosis, or both. International Journal of Cardiology 137(1): 37-41. doi:10.1016/j.ijcard.2008.06.020.

Anderson CM, Overend TJ, Godwin J, Sealy C, Sunderji A (2009) Ambulation after deep vein thrombosis: a systematic review. Physiotherapy Canada 61(3): 133-140. doi:10.3138/physio.61.3.133.

Antonelli M, Conti G, Bufi M, Costa M, Lappa A, Rocco M, Gasparetto A Meduri G (2000) Noninvasive ventilation for treatment of acute respiratory failure in patients undergoing solid organ transplantation: A randomized trial. JAMA: The Journal of the American Medical Association 283(2): 235 241. doi:10.1001/jama.283.2.235.

Antoniou SA, Antoniou GA, Koch OO, Pointner R, Granderath FA (2014) Meta-analysis of laparoscopic vs open cholecystectomy in elderly patients. World Journal of Gastroenterology 20(46): 17626. doi:10.3748/wjg.v20. i46.17626.

Arozullah A (2001) Development and validation of a multifactorial risk index for predicting postoperative pneumonia after major noncardiac surgery Annals of Internal Medicine 135(10): 847-857. doi:10.7326/0003-4819 135-10-200111200-00005.

Arozullah AM, Daley J, Henderson WG, Khuri SF, for the National Veterans Administration Surgical Quality Improvement Program (2000) Multifactorial risk index for predicting postoperative respiratory failure in men after major noncardiac surgery. Annals of Surgery 232(2): 242.

Baltieri L, Santos LA, Rasera-Junior I, Montebelo MIL, Pazzianotto-Forti EM (2014) Use of positive pressure in the bariatric surgery and effects on pulmonary function and prevalence of atelectasis: randomized and blinded clinical trial. Arquivos Brasileiros de Cirurgia Digestiva (São Paulo) 2726-30. doi:10.1590/S0102-6720201400S100007.

Barbalho-Moulim MC, Miguel GPS, Forti EMP, Campos FdA, Costa D (2011) Effects of preoperative inspiratory muscle training in obese women undergoing open bariatric surgery: respiratory muscle strength, lung volumes, and diaphragmatic excursion. Clinics 66(10): 1721-1727. doi:10.1590/S1807-59322011001000009.

Barnett S, Moonesinghe SR (2011) Clinical risk scores to guide perioperative management. Postgraduate Medical Journal 87(1030): 535-541. doi:10.1136/pgmj.2010.107169.

Bellinetti LM, Thomson JC (2006) Respiratory muscle evaluation in elective thoracotomies and laparotomies of the upper abdomen. Jornal Brasileiro de Pneumologia 32(2): 99-105.
Bilgi M, Goksu S, Mizrak A, Cevik C, Gul R, Koruk S, Sahin L (2011) Comparison of the effects of low-flow and high-flow inhalational anaesthesia with nitrous oxide and desflurane on mucociliary activity and pulmonary function tests. European Journal of Anaesthesiology 28(4): 279-283.

Blaney F, Sawyer T (1997) Sonographic measurement of diaphragmatic motion after upper abdominal surgery: A comparison of three breathing manoeuvres. Physiotherapy Theory and Practice 13(3): 207-215. doi:10.1016/S0004-9514(14)60363-9

Boulind C, Yeo M, Burkill C, Witt A, James E, Ewings P, Kennedy R, Francis N (2012) Factors predicting deviation from an enhanced recovery programme and delayed discharge after laparoscopic colorectal surgery. Colorectal Disease 14(3): e103-e110. doi:10.1111/j.1463-1318.2011.02799.

Bourn J, Conway J, Holgate S (1991) The effect of post-operative physiotherapy on pulmonary complications and lung function after upper abdominal surgery. European Respiratory Journal 4325s.

Bouvier A, Rat P, Drissi-Chbihi F, Bonnetain F, Lacaine F, Mariette C, OrtegaDeballon P (2014) Abdominal binders after laparotomy: review of the literature and French survey of policies. Hernia 18(4): 501-506. doi: 10.1007/s10029-014-1264-2.

Browning $L$ (2007) Early mobilisation following upper abdominal surgery in Australian public hospitals. PhD Thesis, Melbourne: University of Melbourne.

Browning L, Denehy L, Scholes RL (2007) The quantity of early upright mobilisation performed following upper abdominal surgery is low: an observational study. Australian Journal of Physiotherapy 53(1): 47-52. doi:10.1016/S0004-9514(07)70061-2

Cash J (1955) Physiotherapy in Some Surgical Conditions (1st edn). London: Faber and Faber.

Cassidy MR, Rosenkranz P, McCabe K, Rosen JE, McAneny D (2013) I COUGH: reducing postoperative pulmonary complications with a multidisciplinary patient care program. JAMA Surgery 148(8): 740-745. doi:10.1001/jamasurg.2013.358.

Castillo R, Haas A (1985) Chest physical therapy: comparative efficacy of preoperative and postoperative in the elderly. Archives of Physical Medicine and Rehabilitation 66(6): 376-379

Cayley WE (2007) Preventing deep vein thrombosis in hospital inpatients. BMJ 335(7611): 147-151. doi:10.1136/bmj.39247.542477.AE.

Cerantola $Y$, Valerio $M$, Persson $B$, Jichlinski P, Ljungqvist O, Hubner $M$, Kassouf W, Muller S, Baldini G, Carli F (2013) Guidelines for perioperative care after radical cystectomy for bladder cancer: Enhanced Recovery After Surgery (ERAS) society recommendations. Clinical Nutrition 32(6): 879887. doi:10.1016/j.clnu.2013.09.014

Cheifetz O, Lucy SD, Overend TJ, Crowe J (2010) The effect of abdominal support on functional outcomes in patients following major abdominal surgery: a randomized controlled trial. Physiotherapy Canada 62(3): 242253. doi:10.3138/physio.62.4.409.

Chen C-H, Huang Y-Z, Hung T-T (2011) Hand-grip strength is a simple and effective outcome predictor in esophageal cancer following esophagectomy with reconstruction: a prospective study. Journal of Cardiothoracic Surgery 6(1): 98. doi:10.1186/1749-8090-6-98.

Chiumello D, Chevallard G, Gregoretti C (2011) Non-invasive ventilation in postoperative patients: a systematic review. Intensive Care Medicine 37(6): 918-929. doi:10.1007/s00134-011-2210-8

Condie E, Hack K, Ross A (1993) An investigation of the value of routine provision of postoperative chest physiotherapy in non-smoking patients undergoing elective abdominal surgery. Physiotherapy 79547-552.

Coolsen MM, Wong-Lun-Hing EM, Dam RM, Wilt AA, Slim K, Lassen $\mathrm{K}$, Dejong $\mathrm{CH}$ (2013) A systematic review of outcomes in patients undergoing liver surgery in an enhanced recovery after surgery pathways. HPB:The Official Journal Of The International Hepato Pancreato Biliary Association 15(4): 245-251. 
Davies SJ, Francis J, Dilley J, Wilson RJT, Howell SJ, Allgar V (2013) Measuring outcomes after major abdominal surgery during hospitalization: reliability and validity of the Postoperative Morbidity Survey. Perioperative Medicine 2(1): 1.

Delaney C, Fazio V, Senagore A, Robinson B, Halverson A, Remzi F (2001) 'Fast track'postoperative management protocol for patients with high comorbidity undergoing complex abdominal and pelvic colorectal surgery. British Journal of Surgery 88(11): 1533-1538.

Denehy L (2001) The physiotherapy management of patients following upper abdominal surgery. PhD thesis, Melbourne: University of Melbourne.

Denehy L, Carroll S, Ntoumenopoulos G, Jenkins S (2001) A randomized controlled trial comparing periodic mask CPAP with physiotherapy after abdominal surgery. Physiotherapy Research International 6(4): 236-250.

Dimick JB, Chen SL, Taheri PA, Henderson WG, Khuri SF, Campbell DA (2004) Hospital costs associated with surgical complications: a report from the private-sector National Surgical Quality Improvement Program. Journal of the American College of Surgeons 199(4): 531-537.

do Nascimento Junior P, Módolo NS, Andrade S, Guimarães MM, Braz LG, El Dib R (2014) Incentive spirometry for prevention of postoperative pulmonary complications in upper abdominal surgery. Cochrane Database of Systematic Reviews (2). doi:10.1002/14651858.CD006058.pub3.

Dols LF, Kok NF, IJzermans JN (2009) Surgical aspects of live kidney donation https://www.bioscience.org/2009/v14/af/3564/fig2.jpg [Accessed 15th March, 2016].

Dronkers J (2008) Prevention of pulmonary complications after upper abdominal surgery by preoperative intensive inspiratory muscle training: a randomized controlled pilot study. Clinical Rehabilitation 22(2): 134-142. doi:10.1177/0269215507081574.

Duggan M, Kavanagh B (2005) Pulmonary Atelectasis A pathogenic perioperative entity. Anesthesiology 102(4): 838-854.

Fagevik Olsén M, Hahn I, Nordgren S, Lonroth H, Lundholm K (1997) Randomized controlled trial of prophylactic chest physiotherapy in major abdominal surgery. British Journal of Surgery 84(11): 1535-1538.

Fagevik Olsen M JK, Lonroth H. (1999) Chest physiotherapy does not improve the outcome in laparoscopic fundoplication and vertical-banded gastroplasty. Surgical Endoscopy 13260-263.

Fagevik Olsén M, Josefson K, Wiklund M (2009) Evaluation of abdominal binder after major upper gastrointestinal surgery. Advances in Physiotherapy 11(2): 104-110. doi:10.1080/14038190802141073.

Feeney C, Reynolds J, Hussey J (2011) Preoperative physical activity levels and postoperative pulmonary complications post-esophagectomy. Diseases of the Esophagus 24(7): 489-494. doi:10.1111/j.1442-2050.2010.01171.x.

Ferreyra GP, Baussano I, Squadrone V, Richiardi L, Marchiaro G, Del Sorbo L, Mascia L, Merletti F, Ranieri VM (2008) Continuous positive airway pressure for treatment of respiratory complications after abdominal surgery: a systematic review and meta-analysis. Annals of Surgery 247(4): 617-626. doi:10.1097/SLA.0b013e3181675829.

Ford G, Whitelaw W, Rosenal T, Cruse P, Guenter C (1983) Diaphragm function after upper abdominal surgery in humans. The American Review of Respiratory Disease 127431-436.

Forti E, Ike D, Barbalho-Moulim M, Rasera I, Costa D (2009) Effects of chest physiotherapy on the respiratory function of postoperative gastroplasty patients. Clinics (Sao Paulo) 64683 - 689. doi:10.1590/S180759322009000700013

Gamsu G, Singer MM, Vincent HH, Berry S, Nadel J (1976) Postoperative impairment of mucous transport in the lung. The American Review of Respiratory Disease 114(4): 673-679.

Gastaldi A, Magalhães C, Baraúna M, Silva E, Souza H (2008) Benefits of postoperative respiratory kinesiotherapy following laparoscopic cholecystectomy. Revista Brasileira de Fisioterapia (2): 100-106.

Grams ST, Ono LM, Noronha MA, Schivinski CIS, Paulin E (2012) Breathing exercises in upper abdominal surgery: a systematic review and metaanalysis. Brazilian Journal of Physical Therapy 16345-353.
Gupta A, Gupta N (2010) Setting up and functioning of a preanaesthetic clinic. Indian Journal of Anaesthesia 54(6): 504. doi:10.4103/00195049.72638

Gustafsson UO, Hausel J, Thorell A, Ljungqvist O, Soop M, Nygren J (2011) Adherence to the enhanced recovery after surgery protocol and outcomes after colorectal cancer surgery. Archives of Surgery 146(5): 571-577. doi:10.1001/archsurg.2010.309.

Guyatt GH, Oxman AD, Vist GE, Kunz R, Falck-Ytter Y, Alonso-Coello P, Schūnemann HJ (2008) GRADE: an emerging consensus on rating quality of evidence and strength of recommendations. BMJ 336(7650): 924-926. doi:10.1136/bmj.39489.470347.AD

Haines KJ, Skinner EH, Berney S (2013) Association of postoperative pulmonary complications with delayed mobilisation following major abdominal surgery: an observational cohort study. Physiotherapy 99(2): 119-125. doi:10.1016/j.physio.2012.05.013

Hamel MB, Henderson WG, Khuri SF, Daley J (2005) Surgical outcomes for patients aged 80 and older: morbidity and mortality from major noncardiac surgery. Journal of the American Geriatrics Society 53(3): 424 429.

Hanekom S, Brooks D, Denehy L, Fagevik-Olsen M, Hardcastle T, Manie S, Louw Q (2012) Reaching consensus on the physiotherapeutic management of patients following upper abdominal surgery: a pragmatic approach to interpret equivocal evidence. BMC Medical Informatics and Decision Making 612. doi:10.1186/1472-6947-12-5

Hedenstierna G, Edmark L (2010) Mechanisms of atelectasis in the perioperative period. Best Practice \& Research Clinical Anaesthesiology 24(2): 157-169.

Holbrook A, Schulman S, Witt DM, Vandvik PO, Fish J, Kovacs MJ, Svensson PJ, Veenstra DL, Crowther M, Guyatt GH (2012) Evidence-based management of anticoagulant therapy: Antithrombotic therapy and prevention of thrombosis, 9th ed: american college of chest physicians evidence-based clinical practice guidelines. CHEST Journal 141(2_suppl): e152S-e184S. doi:10.1378/chest.11-2295

Innocenti D (1996) An overview of the development of breathing exercises into the specialty of physiotherapy for heart and lung conditions. Physiotherapy 82(12): 681-693.

Ireland CJ, Chapman TM, Mathew SF, Herbison GP, Zacharias M (2014) Continuous positive airway pressure (CPAP) during the postoperative period for prevention of postoperative morbidity and mortality following major abdominal surgery. Cochrane Database Syst Rev 8. doi:10.1002/14651858.CD008930.pub2.

Kanat F (2007) Risk factors for postoperative pulmonary complications in upper abdominal surgery. ANZ Journal of Surgery 77(3): 135. doi:10.1111/ j.1445-2197.2006.03993.x.

Kim SH, Na S, Choi J-S, Na SH, Shin S, Koh SO (2010) An evaluation of diaphragmatic movement by M-mode sonography as a predictor of pulmonary dysfunction after upper abdominal surgery. Anesthesia \& Analgesia 110(5): 1349-1354. doi:10.1213/ANE.0b013e3181d5e4d8.

Kindgen-Milles D, Müller E, Buhl R, Böhner H, Ritter D, Sandmann W, Tarnow Jr (2005) Nasal-continuous positive airway pressure reduces pulmonary morbidity and length of hospital stay following thoracoabdominal aortic surgery. CHEST Journal 128(2): 821-828. doi:10.1378/chest.128.2.821.

Knechtle WS, Perez SD, Medbery RL, Gartland BD, Sullivan PS, Knechtle SJ, Kooby DA, Maithel SK, Sarmiento JM, Shaffer VO (2014) The Association Between Hospital Finances and Complications After Complex Abdominal Surgery. Annals of Surgery 262(2): 273-279. doi:10.1097/ SLA.0000000000001042

Koch CG, Li L, Hixson E, Tang A, Phillips S, Henderson JM (2012) What Are the Real Rates of Postoperative Complications: Elucidating Inconsistencies Between Administrative and Clinical Data Sources. Journal of the American College of Surgeons 214(5): 798-805. doi:10.1016/j. jamcollsurg.2011.12.037

Konrad FX, Schreiber T, Brecht-Kraus D, Georgieff M (1993) Bronchial mucus transport in chronic smokers and nonsmokers during general anesthesia. Journal of Clinical Anesthesia 5(5): 375-380. 
Krishna G, Augustine A, Anand R, Mahale A (2013) Chest physiotherapy during immediate postoperative period among patients undergoing laparoscopic surgery- A Randomized Controlled Pilot Trial. International Journal of Biomedical and Advance Research 4(2): 118-122.

Kulkarni S, Fletcher E, McConnell A, Poskitt K, Whyman M (2010) Preoperative inspiratory muscle training preserves postoperative inspiratory muscle strength following major abdominal surgery-a randomised pilot study. Annals of the Royal College of Surgeons of England 92(8): 700-705 doi:10.1308/003588410X12771863936648.

Kuo LJ, Hung CS, Wang W, Tam KW, Lee HC, Liang HH, Chang YJ, Huang MT, Wei PL (2013) Intersphincteric resection for very low rectal cancer: clinical outcomes of open versus laparoscopic approach and multidimensional analysis of the learning curve for laparoscopic surgery. Journal of Surgical Research 183(2): 524-530. doi:http://dx.doi. org/10.1016/j.jss.2013.01.049.

Lång M, Niskanen M, Miettinen P, Alhava E, Takala J (2001) Outcome and resource utilization in gastroenterological surgery. British Journal of Surgery 88(7): 1006-1014. doi:10.1046/j.0007-1323.2001.01812.x.

Larson C, Ratzer E, Davis-Merritt D, Clark J (2009) The effect of abdominal binders on postoperative pulmonary function. The American Surgeon 75(2): 169-171.

Lawrence VA, Cornell JE, Smetana GW (2006) Strategies to reduce postoperative pulmonary complications after noncardiothoracic surgery: systematic review for the American College of Physicians. Annals of Internal Medicine 144(8): 596-608.

Lawrence VA, Hazuda HP, Cornell JE, Pedersen T, Bradshaw P, Mulrow CD, Page CP (2004) Functional independence after major abdominal surgery in the elderly. Journal of the American College of Surgeons 199(5): 762-772.

Lemanu D, Singh P, MacCormick A, Arroll B, Hill A (2013) Effect of Preoperative Exercise on Cardiorespiratory Function and Recovery After Surgery: a Systematic Review. World Journal Of Surgery 37711-720. doi:10.1007/s00268-012-1886-4.

Li C, Ferri LE, Mulder DS, Ncuti A, Neville A, Lee L, Kaneva P, Watson D, Vassiliou M, Carli F, Feldman LS (2012) An enhanced recovery pathway decreases duration of stay after esophagectomy. Surgery 152(4): 606-616. doi:10.1016/j.surg.2012.07.021.

Li S, Liu Y, Peng Q, Xie L, Wang J, Qin X (2013) Chewing gum reduces postoperative ileus following abdominal surgery: A meta $\square$ analysis of 17 randomized controlled trials. Journal of Gastroenterology and Hepatology 28(7): 1122-1132. doi:10.1111/jgh.12206.

Lin D-X, Li X, Ye Q-W, Lin F, Li L-L, Zhang Q-Y (2011) Implementation of a Fast-Track Clinical Pathway Decreases Postoperative Length of Stay and Hospital Charges for Liver Resection. Cell Biochemistry and Biophysics 61(2): 413-419. doi:10.1007/s12013-011-9203-7.

Lunardi A, Paisani D, da Silva CM, Cano D, Carvalho C (2013) Effect of lung expansion techniques in the incidence of pulmonary complications after upper abdominal surgery. European Respiratory Journal 42(Suppl 57): P5076.

Lunardi AC, Cecconello I, Carvalho CRF (2011) Postoperative chest physical therapy prevents respiratory complications in patients undergoing esophagectomy. Brazilian Journal of Physical Therapy / Revista Brasileira de Fisioterapia 15(2): 160-165

Lunardi AC, Paisani DM, da Silva CCM, Cano DP, Tanaka C, Carvalho CR (2015) Comparison of lung expansion techniques on thoracoabdominal mechanics and incidence of pulmonary complications after upper abdominal surgery: a randomized and controlled trial. CHEST Journal. doi:10.1378/chest.14-2696

Lunardi AC, Resende JM, Cerri OM, Carvalho CRFd (2008) Effect of sustained respiratory care until hospital discharge on the incidence of pulmonary complications following esophagectomy for cancer. Fisioterapia e Pesquisa 15(1): 72-77.

Mackay MR, Ellis E, Johnston C (2005) Randomised clinical trial of physiotherapy after open abdominal surgery in high risk patients. Australian Journal of Physiotherapy 51(3): 151-159.
Makhabah DN, Martino F, Ambrosino N (2013) Peri-operative physiotherapy. Multidisciplinary Respiratory Medicine 8(1): 1-6. doi:10.1186/2049-69588-4.

Mans CM, Reeve JC, Elkins MR (2015) Postoperative outcomes following preoperative inspiratory muscle training in patients undergoing cardiothoracic or upper abdominal surgery: a systematic review and meta analysis. Clinical Rehabilitation 29(5): 426-438. doi:10.1177/0269215514545350.

Nakamura M, Iwahashi M, Nakamori M, Ishida K, Naka T, lida T, Katsuda M, Tsuji T, Nakatani Y, Yamaue H (2008) An analysis of the factors contributing to a reduction in the incidence of pulmonary complications following an esophagectomy for esophageal cancer. Langenbeck's Archives of Surgery 393(2): 127-133.

National Institute for Health and Clinical Excellence (NICE) (2010) Venous thromboembolism in adults admitted to hospital: reducing the risk. NICE guidelines [CG92]. http://www.nice.org.uk/guidance/cg92 [Accessed 8/9/2015].

O'Donohue Jr W (1992) Postoperative pulmonary complications. When are preventive and therapeutic measures necessary? Postgraduate Medicine 91(3): 167-170

Olsén MF, Anzén H (2012) Effects of training interventions prior to thoracic or abdominal surgery: a systematic review. Physical Therapy Reviews 17(2): 124-131. doi:10.1179/1743288x11y.0000000054

Orman J, Westerdahl E (2010) Chest physiotherapy with positive expiratory pressure breathing after abdominal and thoracic surgery: a systematic review. Acta Anaesthesiology Scandinavia 54(3): 261-267. doi:10.1111/ j.1399-6576.2009.02143.x

Overend TJ, Anderson CM, Lucy SD, Bhatia C, Jonsson BI, Timmermans C (2001) The Effect of Incentive Spirometry on Postoperative Pulmonary Complications. CHEST Journal 120(3): 971.

Owen RM, Perez SD, Lytle N, Patel A, Davis S, Lin E, Sweeney JF (2013) Impact of operative duration on postoperative pulmonary complications in laparoscopic versus open colectomy. Surgical Endoscopy 27(10): 35553563. doi:10.1007/s00464-013-2949-9.

Paisani DM, Fiore Jr JF, Lunardi AC, Colluci DBB, Santoro IL, Carvalho CRF, Chiavegato LD, Faresin SM (2012) Preoperative 6-min walking distance does not predict pulmonary complications in upper abdominal surgery. Respirology 17(6): 1013-1017. doi:10.1111/j.1440-1843.2012.02202.x.

Park NY, Chong GO, Hong DG, Cho YL, Park IS, Lee YS (2011) Oncologic results and surgical morbidity of laparoscopic nerve-sparing radical hysterectomy in the treatment of FIGO stage IB cervical cancer: long-term follow-up. International Journal of Gynecological Cancer 21(2): 355-362. doi:10.1097/IGC.0b013e31820731bb.

Parry S, Denehy L, Berney S, Browning L (2014) Clinical application of the Melbourne risk prediction tool in a high-risk upper abdominal surgical population: an observational cohort study. Physiotherapy 100(1): 47-53. doi:10.1016/j.physio.2013.05.002.

Pasquina P, Tramèr MR, Granier J-M, Walder B (2006) Respiratory physiotherapy to prevent pulmonary complications after abdominal surgery: A systematic review. CHEST Journal 130(6): 1887-1899.

Pasquina P, Walder B (2003) Prophylactic respiratory physiotherapy after cardiac surgery: systematic review. British Medical Journal 327(7428): 1-6.

Pavy-Le Traon A, Heer M, Narici MV, Rittweger J, Vernikos J (2007) From space to Earth: advances in human physiology from 20 years of bed rest studies (1986-2006). European Journal of Applied Physiology 101(2): 143194.

Pouwels S, Stokmans RA, Willigendael EM, Nienhuijs SW, Rosman C, van Ramshorst B, Teijink JA (2014) Preoperative exercise therapy for elective major abdominal surgery: A systematic review. International Journal of Surgery 12(2): 134-140. doi:10.1016/j.ijsu.2013.11.018.

Pouwels S, Willigendael E, van Sambeek M, Nienhuijs S, Cuypers P, Teijink J (2015) Beneficial Effects of pre-operative exercise therapy in patients with an abdominal aortic aneurysm: a systematic review. European Journal of Vascular and Endovascular Surgery 49(1): 66-76. 
PROVHILO group (2014) High versus low positive end-expiratory pressure during general anaesthesia for open abdominal surgery (PROVHILO trial): a multicentre randomised controlled trial. The Lancet 384(9942): 495-503. doi:http://dx.doi.org/10.1016/S0140-6736(14)60416-5.

Reeve JC, Nicol K, Stiller K, McPherson KM, Birch P, Gordon IR, Denehy $L$ (2010) Does physiotherapy reduce the incidence of postoperative pulmonary complications following pulmonary resection via open thoracotomy? A preliminary randomised single-blind clinical trial. European Journal of Cardio-Thoracic Surgery 37(5): 1158-1166. doi:10.1016/j. ejcts.2009.12.011

Rothman JP, Gunnarsson U, Bisgaard T (2014) Abdominal binders may reduce pain and improve physical function after major abdominal surgery - a systematic review. Danish Medical Journal 61(11): A4941.

Rotta BP, da Silva JM, Padovani C, da Silveira LTY, Mafra JM, Fu C, Tanaka C (2013) Postoperative pulmonary complications are associated to higher ICU cost. European Respiratory Journal 42(Suppl 57): P287.

Said E (2008) PACES resources, MRCP (UK) Practical Assessment of Clinical Examination Skills. http://mrcppreview.blogspot.co.nz/2008/06/scaragain. html [Accessed 15th March, 2016].

Samnani SS, Umer MF, Mehdi SH, Farid FN (2014) Impact of preoperative counselling on early postoperative mobilization and its role in smooth recovery. International Scholarly Research Notices 1-4.

Santa Mina D, Matthew AG, Hilton WJ, Au D, Awasthi R, Alibhai SM Clarke H, Ritvo P, Trachtenberg J, Fleshner NE (2014) Prehabilitation for men undergoing radical prostatectomy: a multi-centre, pilot randomized controlled trial. BMC Surgery 14(1): 89. doi:10.1186/1471-2482-14-89.

Scholes R, Denehy L, Sztendur E, Browning L (2006) A survey of Australian physiotherapy management of patients having abdominal surgery. Australian Journal of Physiotherapy S26 (abstract).

Scholes RL, Browning L, Sztendur EM, Denehy L (2009) Duration of anaesthesia, type of surgery, respiratory co-morbidity, predicted VO max and smoking predict postoperative pulmonary complications after upper abdominal surgery: an observational study. Australian Journal of Physiotherapy 55(3): 191-198.

Serejo LGG, da Silva-Júnior FP, Bastos JPC, de Bruin GS, Mota RMS, de Bruin PFC (2007) Risk factors for pulmonary complications after emergency abdominal surgery. Respiratory Medicine 101(4): 808-813. doi:10.1016/j. rmed.2006.07.015.

Silva Y, Li S, Rickard M (2013) Does the addition of deep breathing exercises to physiotherapy-directed early mobilisation alter patient outcomes following high-risk open upper abdominal surgery? Physiotherapy 99(3): 187-193. doi:10.1016/j.physio.2012.09.006.

Singh F, Newton RU, Galvão DA, Spry N, Baker MK (2013) A systematic review of pre-surgical exercise intervention studies with cancer patients. Surgical Oncology 22(2): 92-104. doi:10.1016/j.suronc.2013.01.004.

Smith $M$, Ellis E (2000) Is retained mucus a risk factor for the development of postoperative atelectasis and pneumonia? Implications for the physiotherapist. Physiotherapy Theory and Practice 1669-80.

Smith PR, Baig MA, Brito V, Bader F, Bergman MI, Alfonso A (2009a) Postoperative pulmonary complications after laparotomy. Respiration 80(4): 269-274. doi:10.1159/000253881.

Smith T, Stonell C, Purkayastha S, Paraskevas P (2009b) Cardiopulmonary exercise testing as a risk assessment method in non cardio-pulmonary surgery: a systematic review. Anaesthesia 64(8): 883-893. doi:10.1111/ j.1365-2044.2009.05983.x.
Spanjersberg W, van Sambeeck J, Bremers A, Rosman C, van Laarhoven C (2015) Systematic review and meta-analysis for laparoscopic versus open colon surgery with or without an ERAS programme. Surgical Endoscopy 1-11. doi:10.1007/s00464-015-4148-3.

Stock M, Downs J, Gauer P, Alster J, Imrey P (1985) Prevention of postoperative pulmonary complications with CPAP, incentive spirometry, and conservative therapy. CHEST Journal 87(2): 151-157.

Story SK, Chamberlain RS (2009) A comprehensive review of evidence-based strategies to prevent and treat postoperative ileus. Digestive Surgery 26(4): 265-275. doi:10.1159/000227765.

Thompson DA, Makary MA, Dorman T, Pronovost PJ (2006) Clinical and economic outcomes of hospital acquired pneumonia in intra-abdominal surgery patients. Annals of Surgery 243(4): 547-552.

Tusman G, Böhm SH, Warner DO, Sprung J (2012) Atelectasis and perioperative pulmonary complications in high-risk patients. Current Opinion in Anesthesiology 25(1): 1-10. doi:10.1097/ ACO.0b013e32834dd1eb.

Valkenet K, van de Port IGL, Dronkers JJ, de Vries WR, Lindeman E, Backx FJG (2011) The effects of preoperative exercise therapy on postoperative outcome: a systematic review. Clinical Rehabilitation 25(2): 99-111. doi:10.1177/0269215510380830

Varadhan KK, Neal KR, Dejong CH, Fearon KC, Ljungqvist O, Lobo DN (2010) The enhanced recovery after surgery (ERAS) pathway for patients undergoing major elective open colorectal surgery: a meta-analysis of randomized controlled trials. Clinical Nutrition 29(4): 434-440. doi:10.1016/j.clnu.2010.01.004.

Vather R, Trivedi S, Bissett I (2013) Defining postoperative ileus: results of a systematic review and global survey. Journal of Gastrointestinal Surgery 17(5): 962-972. doi:10.1007/s11605-013-2148-y.

Weiser TG, Regenbogen SE, Thompson KD, Haynes AB, Lipsitz SR, Berry WR, Gawande AA (2008) An estimation of the global volume of surgery: a modelling strategy based on available data. The Lancet 372(9633): 139144. doi:10.1016/S0140-6736(08)60878-8.

Westwood K, Griffin M, Roberts K, Williams M, Yoong K, Digger T (2007) Incentive spirometry decreases respiratory complications following major abdominal surgery. The Surgeon 5(6): 339-342.

Wijk L, Franzen K, Ljungqvist O, Nilsson K (2014) Implementing a structured Enhanced Recovery After Surgery (ERAS) protocol reduces length of stay after abdominal hysterectomy. Acta Obstetricia et Gynecologica Scandinavica. doi:10.1111/aogs.12423.

Wynne R (2004) Variable definition: Implications for the prediction of pulmonary complications after adult cardiac surgery. European Journal of Cardiovascular nursing 3(1): 43-52.

Zhang X-y, Wang Q, Zhang S, Tan W, Wang Z, Li J (2015) The use of a modified, oscillating positive expiratory pressure device reduced fever and length of hospital stay in patients after thoracic and upper abdominal surgery: a random Journal of Physiotherapy 61(1): 16-20. doi:10.1016/j. jphys.2014.11.013 